\title{
Tunable single-site ruthenium catalysts for efficient water oxidation $\uparrow$
}

\author{
Lucile Bernet, ${ }^{a}$ Ralte Lalrempuia, ${ }^{a}$ Wadih Ghattas, ${ }^{a}$ Helge Mueller-Bunz, ${ }^{a}$ Laura Vigara,${ }^{b}$ Antoni \\ Llobet $^{* b}$ and Martin Albrecht $* a$
}

\author{
Receipt/Acceptance Data [DO NOT ALTER/DELETE THIS TEXT] \\ Publication data [DO NOT ALTER/DELETE THIS TEXT] \\ DOI: 10.1039/b000000x [DO NOT ALTER/DELETE THIS TEXT]
}

\begin{abstract}
The catalytic water oxidation activity of mononuclear ruthenium complexes comprising a pyridine-functionalized abnormal triazolylidene ligand can be adjusted by modifcation of the triazolylidene substituents, which is readily achieved through click-type cycloaddition chemistry, affording some of the most active ruthenium catalyst known thus far for water oxidation (TONs $>400$, TOFs close to $7000 \mathrm{~h}^{-1}$ ).
\end{abstract}

Efficient water splitting is one of the grand challenges in current chemical research, aiming at disclosing new fuel technologies for covering the increasingly growing global energy needs. ${ }^{1}$ While catalysts for water reduction have been available for long time, efficient water oxidizing methodologies are much rarer. $^{2}$ This lack is in part due to the high potential and molecular complexity that need to be overcome in order to accomplish the 4-electron transfer required to generate $\mathrm{O}_{2}$ from $\mathrm{H}_{2} \mathrm{O}$.

The natural evolution of $\mathrm{O}_{2}$ at the $\mathrm{Mn}_{4}$ core of photosystem $\mathrm{II}^{3}$ has provided much stimulation for synthetic advances. ${ }^{4}$ Multimetallic systems, ${ }^{5}$ including clusters, ${ }^{6}$ have been implemented in an attempt to distribute the multielectron transfer over several active sites, thus lowering the number of accessible oxidation states needed for a given metal center. Monometallic complexes, which may offer advantages such as facile ligand tunability and the deduction of structure-activity relationships, have only recently been reported to be active in water oxidation. ${ }^{7}$ While in some cases, the accessibility of less usual oxidation states has been proposed, ${ }^{7,8}$ other systems introduced ligand cooperativity in order to accommodate the extra charges (and holes) during the catalytic cycle. $^{9}$ Abnormal carbenes such as 1,2,3-triazol-5-ylidenes ${ }^{10}$ may be particularly suitable for such cooperative behavior, as these ligands feature a pronounced mesoionic resonance contribution that entails simultaneously electron accepting and donating properties. The recent application of this ligand in the ruthenium-catalyzed base-free oxidation of alcohols may underpin this concept. ${ }^{11}$ Moreover, mononuclear iridium triazolylidene complexes have shown to be highly active in water oxidation, reaching turnover numbers (TONs) around 10,000. ${ }^{12}$ Here we report on the expansion of this approach to monometallic ruthenium complexes containing an easily tunable chelating triazolylidene ligand functionalized with a pyridyl donor. Tailoring of the catalytic activity, still rare in water oxidation catalysis, is readily achieved by appropriate modification of the substituent at the triazolylidene nitrogens.

The triazolium salts used as carbene precursors were readily

$\uparrow$ Electronic Supplementary Information (ESI) available: Experimental procedures for ligands $\mathbf{1}$, and complexes $\mathbf{2}$ and $\mathbf{3}$, details on catalytic experiments, and crystallographic details for complexes $\mathbf{2 a}, \mathbf{2 b}, \mathbf{2 c}, \mathbf{3 a}$, 3b, 3c, 3d, 4, and 5. See http://www.rsc.org/suppdata/xx/b0/b000000x/ *martin.albrecht@ucd.ie; allobet@iciq.es

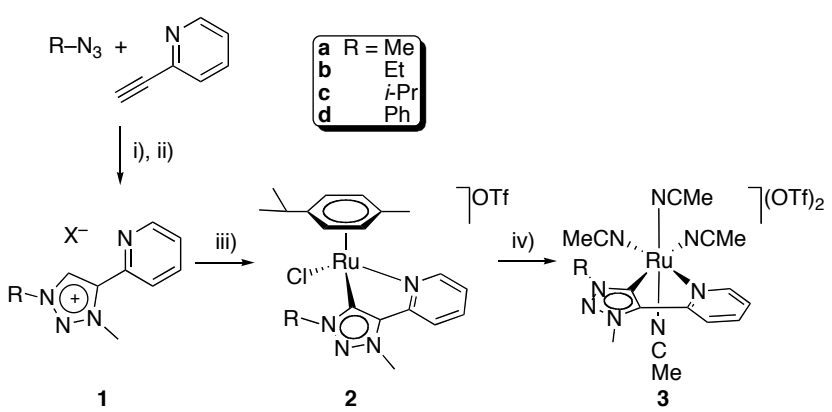

Scheme 1 Reagents and conditions: i) $\mathrm{CuSO}_{4}, \mathrm{Na}$-ascorbate, $\mathrm{THF} / \mathrm{H}_{2} \mathrm{O}$ (1:1), $100^{\circ} \mathrm{C}$, microwave for $30 \mathrm{~min}(82-95 \%)$; ii) $\mathrm{MeOTf}, \mathrm{CH}_{2} \mathrm{Cl}_{2}, 0^{\circ} \mathrm{C}$ for $30 \mathrm{~min}(22-25 \%)$ iii) $\mathrm{Ag}_{2} \mathrm{O},\left[\mathrm{Ru}(\mathrm{cym}) \mathrm{Cl}_{2}\right]_{2}, \mathrm{MeCN}, 35^{\circ} \mathrm{C}$ for $2 \mathrm{~d}(38-$ $54 \%$ ); iv) AgOTf, MeCN, reflux, 18 h (73-89\%).

accessible via $\mathrm{Cu}$-mediated [3+2] cycloaddition of azides and alkynes, ${ }^{13}$ and subsequent methylation at the triazole N3 position (Scheme 1) $\$$ The ruthenium complexes 2 were prepared from the corresponding pyridine-substituted triazolium salts 1 with $\mathrm{Ag}_{2} \mathrm{O}$ and subsequent transmetalation using $\left[\mathrm{Ru} \text { (cymene) } \mathrm{Cl}_{2}\right]_{2}$. Halide abstraction from 2 with AgOTf and thermal cymene dissociation in refluxing $\mathrm{MeCN}$ afforded the dicationic solvento complexes $\mathbf{3}$ in appreciable yields. ${ }^{14}$ The formation of the triazolylidene complexes 2 was indicated by NMR spectroscopy, which revealed the disappearance of the resonance around $\delta_{\mathrm{H}} 8.5$ assigned to the triazolium proton in $1\left(\mathrm{CD}_{3} \mathrm{CN}\right.$ solution). In the ${ }^{13} \mathrm{C} \mathrm{NMR}$ spectrum, the ruthenium-bound carbon appears around $172 \mathrm{ppm}$, corresponding to an approximate $20 \mathrm{ppm}$ downfield shift as compared to the ligand precursor. The exact chemical shift is dependent on the substitutent at nitrogen $\left(\delta_{\mathrm{C}} 174.1,172.9,172.4\right.$, and 174.0 for $\mathbf{2 a - 2 d}$, respectively), pointing to a moderate tunability of the electron density at this carbon via wingtip substitution. ${ }^{15}$ Chelation of the pyridine unit in solution is supported by the highfield resonance of the proton in the pyridine ortho position, which shifted from $\delta_{\mathrm{H}} 8.4$ in 1 to 9.4. The corresponding dicationic acetonitrile complexes $\mathbf{3}$ displayed similar spectroscopic characteristics for the bidentate triazolylidene ligand. Most diagnostic is the absence of the resonances due to the cymene ligand, and the upfield shift of the ortho-pyridine $\mathrm{H}$ to $\delta_{\mathrm{H}} 9.1$. In the ${ }^{13} \mathrm{C}$ NMR spectrum, the ruthenium-bound carbon experiences a slight yet noticeable shift. In particular, the different sequence $\left(\delta_{C}\right.$ $176.3,174.5,172.3$, and 168.4 for 3a-3d, respectively) suggests some flexibility of the ligand in responding to the altered electronic environment at the ruthenium center in cationic $\mathbf{2}$ and dicationic 3 .

Evidence for the connectivity pattern in complexes $\mathbf{2}$ and $\mathbf{3}$ was obtained by $\mathrm{X}$-ray crystallographic analyses. $\dagger$ The molecular structures of complexes $\mathbf{2 a}$ and $\mathbf{3 a}$ are representative and confirm the $C, N$-bidentate chelation of the ligand as deduced from solution 

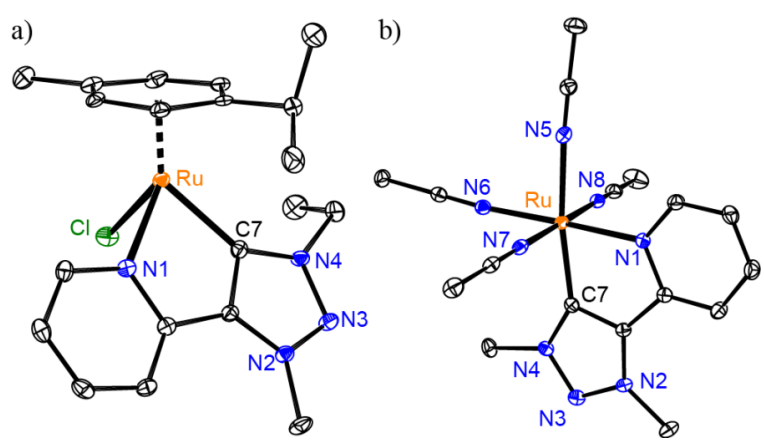

Fig. 1 ORTEP representation of complex $\mathbf{2 a}$ (a) and complex $\mathbf{3 a}(\mathrm{b} ; 50 \%$ probability ellipsoids, non-coordinating anions and hydrogens omitted for clarity). Selected bond lengths $(\AA)$ and angles $\left({ }^{\circ}\right)$ for $\mathbf{2 a}$ : Ru-C1 2.032(1), $\mathrm{Ru}-\mathrm{N} 4$ 2.126(1), Ru-Cl 2.4036(3), C1-Ru-N4 76.53(4); for 3a: $\mathrm{Ru}-\mathrm{C} 7$ 1.9922(13), Ru-N1 2.0954(11), Ru-N5 2.1166(12), Ru-N6 2.0315(11), C7-Ru-N1 78.34(5).

studies (Fig. 1). While the $\mathrm{Ru}-\mathrm{C}$ bond lengths fall within the expected 2.0-2.1 $\AA$ range, ${ }^{16}$ subtle differences have been noted. In the dicationic complexes 3, the $\mathrm{Ru}-\mathrm{C}$ bond distance is 1.999(6) $\AA$ and hence significantly shorter than in the monocationic complexes 2 (Ru- $\left.\mathrm{C}_{\text {triazolylidene }} 2.028(7) \AA\right)$. Likewise, the $\mathrm{Ru}$-pyridine distance shrinks from 2.129(7) $\AA$ in 2 to 2.092(3) $\AA$ in 3. As a consequence of these bond length variations, the ligand bite angle is slightly larger (78.6(12) in $\mathbf{3}$ vs 76.59(6) in 2), though it remains rather acute. In complexes 3 , the $\mathrm{Ru}-\mathrm{N}_{\mathrm{MeCN}}$ bond lengths trans to the triazolylidene ligand average to 2.114(7) $\AA$ and are thus about 0.08 $\AA$ longer than the analogous bonds trans to the pyridine ligand (Ru-N 2.032(2) $\AA$ ), reflecting the markedly stronger trans influence of the triazolyidene ligand as compared to pyridine.

Electrochemical analyses of the complexes revealed a quasireversible oxidation at $1.42 \mathrm{~V}$ ( $v s$. SCE) for complexes 2 and at slightly lower potential for complexes 3 (Table 1). Analysis of the oxidation potentials demonstrates a close correlation between electron donor ability of the wingtip group and the ruthenium oxidation potential. Thus, complex $\mathbf{2 d}$ comprising a withdrawing $\mathrm{Ph}$ substituent displays the highest oxidation potential $\left(E_{1 / 2}=1.445\right.$ $\mathrm{V})$ and this potential decreases with increasing donor ability of the substituent $\mathrm{R}\left(E_{1 / 2}=1.433 \mathrm{~V}\right.$ for $\mathrm{R}=\mathrm{Me}, 1.427$ for $\mathrm{R}=\mathrm{Et}$, and 1.425 for $\mathrm{R}=i$ - $\mathrm{Pr}$ ). A different trend was observed in the dicationic complexes 3 with the oxidation potential increasing from $\mathrm{Me}<i-\mathrm{Pr}$ $<$ Et $<<$ Ph.§ Possibly, stereoelectronic effects may become more dominant in these formally octahedral complexes. Accordingly, bulky substituents at the triazole nitrogen may interfere with the cis coordinating $\mathrm{MeCN}$ ligand, resulting in significant distortion from ideal octahedral geometry and thus reducing the ligands' donor ability into relevant $d$ orbitals. Such a model is further supported by solid-state analyses, which reveal that the angle between the pyridyl nitrogen and the trans coordinated $\mathrm{MeCN}$ (i.e. cis to the triazolylidene) deviates more distinctively in $\mathbf{3 b}$ and $\mathbf{3} \mathbf{c}$ than in $\mathbf{3 a}$.

Complexes $\mathbf{2}$ and $\mathbf{3}$ were all active in the oxidation of water using $\mathrm{Ce}^{\mathrm{IV}}$ as sacrificial oxidant (Table 1). The cymene-containing complexes 2 generated substantial amounts of $\mathrm{CO}_{2}$ along with $\mathrm{O}_{2}$ according to mass spectrometric analysis of the products. The relative $\mathrm{CO}_{2}$ portion gradually increased over time, and was considerably higher with bulkier N-substituent, increasing in the order $\mathrm{Me}<\mathrm{Et}<i$ - $\mathrm{Pr}<\mathrm{Ph}$. In contrast the corresponding dicationic complexes 3 produced $\mathrm{O}_{2}$ exclusively. We therefore assume that cymene rather than the carbene ligand is sensitive towards
Table 1 Electrochemical data ${ }^{a}$ and water oxidation activity ${ }^{b}$ of $\mathbf{2 - 5}$

$\begin{array}{llllll}\text { Complex } & E_{1 / 2}(\mathrm{~V}) & \mathrm{rel}_{2}(\%)^{c} & \mathrm{rel} \mathrm{CO} \mathrm{CO}_{2}(\%)^{c} & \mathrm{TOF}_{1000 \mathrm{~s}}\left(\mathrm{~h}^{-1}\right)^{d} & \mathrm{TON} \\ \mathbf{2 a} & +1.433 & 99 & 1 & 198 & 18 \\ \mathbf{2 b} & +1.427 & 98 & 2 & 144 & 11 \\ \mathbf{2 c} & +1.425 & 83 & 17 & 21 & 1.0 \\ \mathbf{2 d} & +1.445 & 66 & 34 & 25 & 2.0 \\ \mathbf{3 a} & +1.358 & >99.5 & <0.5 & 1080 & 19 \\ \mathbf{3 b} & +1.368 & >99.5 & <0.5 & 612 & 14 \\ \mathbf{3 c} & +1.363 & >99.5 & <0.5 & 576 & 13 \\ \mathbf{3 d} & +1.42^{e} & 99 & 1 & 216 & 10 \\ \mathbf{4} & +1.500 & 97 & 3 & 7 & 2.4 \\ \mathbf{5} & \text { n.a. } & 97 & 3 & 7 & 13\end{array}$

a Potentials from differential pulse voltammetry using $\mathrm{Bu}_{4} \mathrm{NPF}_{6}$ as supporting electrolyte and referenced to $\mathrm{SCE}$ using $\mathrm{Fc}^{+} / \mathrm{Fc}$ as internal standard; complexes 2 measured in $\mathrm{CH}_{2} \mathrm{Cl}_{2}\left(\mathrm{Fc}^{+} / \mathrm{Fc}+0.46\right.$ vs $\left.\mathrm{SCE}\right)$, complexes 3-4 in $\mathrm{MeNO}_{2}\left(\mathrm{Fc}^{+} / \mathrm{Fc}+0.35\right.$ vs $\left.\mathrm{SCE}\right) .{ }^{b}$ Catalytic runs performed with catalyst $(1 \mathrm{mM})$, oxidant $(100 \mathrm{mM})$ in triflic acid solution $(0.1 \mathrm{M}, \mathrm{pH}=1.0 ; 2.0 \mathrm{~mL}) .{ }^{c}$ relative $\mathrm{O}_{2}$ and $\mathrm{CO}_{2}$ concentrations measured by MS after $100 \mathrm{~s}^{d}{ }^{d} \mathrm{TOF}_{1000 \mathrm{~s}}$ is the turnover frequency after $1000 \mathrm{~s} .{ }^{e}$ broad oxidation and reduction peaks.

oxidation. Bulky wingtip groups induce steric congestion and thus tend to facilitate cymene dissociation.

The dicationic complexes $\mathbf{3}$ are oxidatively stable, producing essentially no detectable $\mathrm{CO}_{2}$, and showing appreciable activity towards $\mathrm{O}_{2}$ formation. Complex $\mathbf{3 d}$ is an exception and revealed small but noticeable quantities of $\mathrm{CO}_{2}$, which may be related to the propensity of N-bound phenyl groups to undergo cyclometalation. ${ }^{15}$ Complex 3a as the most active catalyst precursor of the series was further evaluated under different reaction conditions. At a 1:100 catalyst/oxidant ratio (1 $\mathrm{mM}$ catalyst), a marked reduction of catalyst performance was observed after about 10 turnovers, perhaps due to the formation of catalytically inactive dimeric species at high ruthenium concentrations. At a 1:10,000 catalysts/oxidant ratio $(0.025 \mathrm{mM}$ catalyst $)$, the turnover numbers (TONs) increased substantially, reaching 105 mols $\mathrm{O}_{2}$ per mol ruthenium after $45 \mathrm{~min}$ (i.e. 420 turnovers), and oxidation activity was still ongoing. Hence, catalyst deactivation is efficiently suppressed under dilute reaction conditions.

Catalytic runs at different concentrations indicate a linear relationship between the concentration and the initial turnover frequency, thus supporting homogeneous $\mathrm{O}_{2}$ production at molecular catalytic sites rather than at aggregates. At an $8 \mathrm{mM}$ complex concentration (1:100 catalyst/oxidant), initial turnover frequencies as high as $6660 \mathrm{~h}^{-1}$ were observed. These initial rates are amongst the highest for mono- and dimetallic ruthenium complexes reported to date. ${ }^{17}$ In particular the methyl-substituted complexes 3a is about 100 times more active than previously tested pyridine- and phthalazine-based mononuclear ruthenium complexes. ${ }^{5,7}$ The overall TONs seem to correlate with the stereoelectronic effects deduced from electrochemical analyses and thus point to the relevance of electron donating groups for providing easy access to higher oxidation states.

Comparison of complex 3a with the homologous and sterically similar complex 4 comprising a normal imidazol-2-ylidene NHC ligand (Fig. 2) showed the latter complex to be a poor catalyst, providing significant quantities of $\mathrm{CO}_{2}$ as well as low TONs and TOFs. These activity differences thus underline the advantageous role of the abnormal triazolylidene scaffold. Possibly, triazolylidene ligands may cooperatively assist bond cleavage and oxidation processes through reversible tautomerization of the mesoionic triazolylidene ruthenium aqua complex $\mathbf{A}$ to a carbene- 

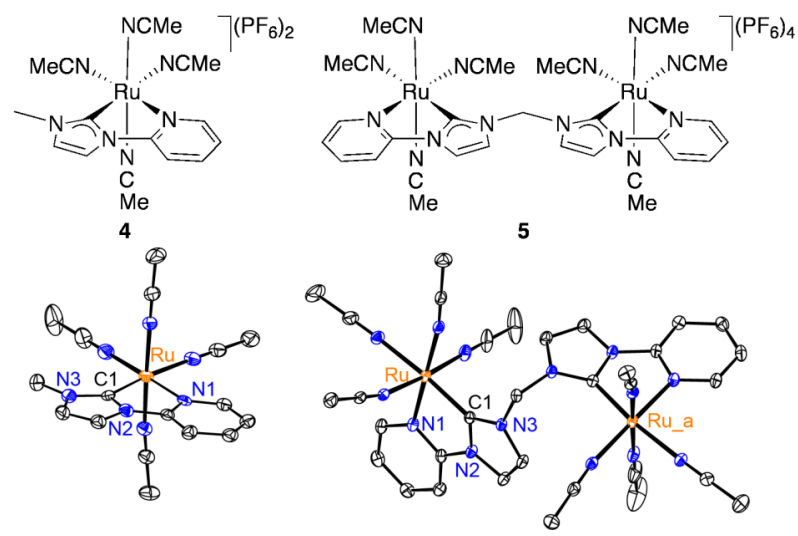

Fig. 2 Schematic drawing and ORTEP plots of monometallic complex 4 comprising a normal carbene ligand and its dimetallic homologue $\mathbf{5}$.

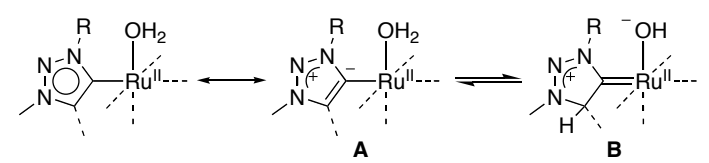

Scheme 2 Possible ligand-cooperative water activation imparted by the strong mesoionic resonance contribution in abnormal carbenes.

type hydroxide complex B (Scheme 2), thus transforming the neutral water ligand into an anionic hydroxide without formally changing the metal oxidation state. Further support for a different (and less efficient) pathway for water oxidation with normal carbene ruthenium complexes may be deduced from the higher TONs accomplished with the dimetallic species $\mathbf{5}$ compared to the monometallic analogue 4, though also the bimetallic system produces considerably more $\mathrm{CO}_{2}$ and is kinetically less competent than the triazolylidene complexes $\mathbf{3}$.

In summary, a new and simple family of ruthenium-based water oxidation catalysts has been developed. The complexes are readily accessible, and the core triazolylidene ligand is broadly tunable via flexible click-type [3+2] cycloaddition synthesis. The catalytic activity is remarkable, in particular when considering the low complexity of the ligand system, which may become useful for designing synthetic devices for efficient water splitting.

We thank the European Research Council (ERC-StG 208651) and Science Foundation Ireland, in parts under the Solar Energy Conversion Strategic Research Cluster, for funding.

Lucile Bernet, ${ }^{a}$ Ralte Lalrempuia, ${ }^{a}$ Wadih Ghattas, ${ }^{a}$ Helge MuellerBunz, ${ }^{a}$ Laura Vigara, ${ }^{b}$ Antoni Llobet ${ }^{* b}$ and Martin Albrecht ${ }^{* a}$

${ }^{a}$ School of Chemistry \& Chemical Biology, University College Dublin, Belfield, Dublin 4, Ireland. Fax: +353 1716 2501; Tel: +353 1716 2504; E-mail: martin.albrecht@ucd.ie

${ }^{b}$ Institute of Chemical Research of Catalonia (ICIQ), Av. Paisos Catalans 16, E-43007 Tarragona, Spain. Fax: +34 977 920228; Tel: +34 977 920815;E-mail: allobet@iciq.es

\section{Notes and references}

\$ The reaction of the pyridine-functionalized triazole with MeOTf was not chemoselective and gave mixtures of the triazolium and the pyridinium salt, indicated by the ${ }^{1} \mathrm{H}$ NMR shift of the pertinent heterocyclic protons; they were separated by preparative TLC.

$\S$ The DPV data for complex 3d suggest a more complex process than simple reversible metal oxidation.

1 N. S. Lewis and D. G. Nocera, Proc. Natl. Acad. Sci. USA 2006, 103 15729; V. Balzani, A. Credi and M. Venturi, ChemSusChem 2008, 1, 26; N. D. McDaniel and S. Bernhard, Dalton Trans. 2010, 39, 10021.
2 See for examples: (a) M. Grätzel, Acc. Chem. Res. 1981, 14, 376; J. R. Darwent, P. Douglas, A. Harriman, G. Porter and M. C. Richoux, Coord. Chem. Rev. 1982, 44, 83; R. Eisenberg and H. B. Gray, Inorg. Chem. 2008, 47, 1697; H. Dau, C. Limberg, T. Reier, M. Risch, S. Roggan and P. Strasser, Chem CatChem 2010, 2, 724.

3 A. W. Rutherford, A. Boussac, Science, 2004, 303, 1831.

4 M. Yagi and M. Kaneko, Chem. Rev., 2001, 101, 21.

5 S. W. Gersten, G. J. Samuels and T. J. Meyer, J. Am. Chem. Soc., 1982, 104, 4029; C. Sens, I. Romero, M. Rodriguez, A. Llobet, T. Parella and J. Benet-Buchholz, J. Am. Chem. Soc., 2004, 126, 7798; R. Zong and R. P. Thummel, J. Am. Chem. Soc., 2005, 127, 12802; Z. Deng, H. Tseng, R. Zong, D. Wang and R. Thummel, Inorg. Chem., 2008, 47, 1835; A. Sartorel, M. Carraro, G. Scorrano, R. De Zorzi, S. Geremia, N. D. McDaniel, S. Bernhard and M. Bonchio, J. Am. Chem. Soc., 2008, 130, 5006; Y. V. Geletii, B. Botar, P. Koegerler, D. A. Hillesheim, D. G. Musaev and C. L. Hill, Angew. Chem., Int. Ed., 2008, 47, 3896; A. Sartorel, P. Miro, E. Salvadori, S. Romain, M. Carraro, G. Scorrano, M. Di Valentin, A. Llobet, C. Bo and M. Bonchio, J. Am. Chem. Soc., 2009, 131, 16051.

6 M. W. Kanan and D. G. Nocera, Science, 2008, 321, 1072; Y. Surendranath, M. Dinca and D. G. Nocera, J. Am. Chem. Soc., 2009, 131, 2615; E. M. P. Steinmiller and K. S. Choi, Proc. Natl. Acad. Sci. USA, 2009, 106, 20633; Q. Yin, J. M. Tan, C. Besson, Y. V. Geletii, D. G. Musaev, A. E. Kuznetsov, Z. Luo, K. I. Hardcastle and C. L. Hill, Science, 2010, 328, 342; M. Dinca, Y. Surendranath and D. G. Nocera, Proc. Natl. Acad. Sci. USA, 2010, 107, 10337; S. D. Tilley, M. Cornuz, K. Sivula and M. Grätzel, Angew. Chem., Int. Ed., 2010, 49, 6405 .

7 T. J. Meyer and M. H. V. Huynh, Inorg. Chem., 2005, 44, 8140; N. D. McDaniel, F. J. Coughlin, L. L. Tinker and S. Bernhard, J. Am. Chem. Soc., 2008, 130, 210; J. F. Hull, D. Balcells, J. D. Blakemore, C. D. Incarvito, O. Eisenstein, G. W. Brudvig and R. H. Crabtree, $J$. Am. Chem. Soc., 2009, 131, 8731; W. C. Ellis, N. D. McDaniel, S. Bernhard and T. J. Collins, J. Am. Chem. Soc., 2010, 132, 10990; J. D. Blakemore, N. D. Schley, D. Balcells, J. F. Hull, G. W. Olack, C. D. Incarvito, O. Eisenstein, G. W. Brudvig and R. H. Crabtree, J. Am. Chem. Soc., 2010, 132, 16017; M. Yagi, S. Tajima, M. Komi and H. Yamazaki, Dalton Trans., 2011, 40, 3802.

8 T. P. Brewster, J. D. Blakemore, N. D. Schley, C. D. Incarvito, N. Hazari, G. W. Brudvig and R. H. Crabtree, Organometallics, 2011, 30, 965 .

9 S. W. Kohl, L. Weiner, L. Schwartsburd, L. Konstantinovski, L. J. W. Shimon, Y. Ben-David, M. A. Iron and D. Milstein, Science, 2009, 324, 74; T. Zweifel, J.-V. Naubron and H. Grützmacher, Angew. Chem., Int. Ed., 2009, 48, 559.

10 M. Albrecht, Chem. Commun., 2008, 3601; O. Schuster, L. Yang, H. G. Raubenheimer and M. Albrecht, Chem. Rev., 2009, 109, 3445; P. Mathew, A. Neels and M. Albrecht, J. Am. Chem. Soc., 2008, 130, 13534; G. Guisado-Barrios, J. Bouffard, B. Donnadieu and G. Bertrand, Angew. Chem., Int. Ed., 2010, 49, 4759; T. Nakamura, K. Ogata and S. Fukuzawa, Chem. Lett., 2010, 39, 920; K. J. Kilpin, U. S. D. Paul, A.-L. Lee and J. D. Crowley, Chem. Commun., 2011, 47, 328.

11 A. Prades, E. Peris and M. Albrecht, Organometallics, 2011, 30, 1162.

12 R. Lalrempuia, N. D. McDaniel, H. Mueller-Bunz, S. Bernhard and M. Albrecht, Angew. Chem., Int. Ed., 2010, 49, 9765.

13 R. Huisgen, Angew. Chem., Int. Ed., 1963, 2, 565; M. Meldal and C. W. Tornoe, Chem. Rev., 2008, 108, 2952; M. G. Finn and V. V. Fokin, Chem. Soc. Rev., 2010, 39, 1231 (themed issue).

14 W. Ghattas, H. Müller-Bunz and M. Albrecht, Organometallics, 2010, 29, 6782.

15 A. Poulain, D. Canseco-Gonzalez, R. Hynes-Roche, H. Müller-Bunz, O. Schuster, H. Stoeckli-Evans, A. Neels and M. Albrecht, Organometallics, 2011, 30, 1021.

16 See for examples: (a) J. Huang, E. D. Stevens, S. P. Nolan and J. L. Petersen, J. Am. Chem. Soc., 1999, 121, 2674; M. Poyatos, E. MasMarza, M. Sanau and E. Peris, Inorg. Chem., 2004, 43, 1793; L. Mercs, A. Neels and M. Albrecht, Dalton Trans., 2008, 5570; C. Gandolfi, M. Heckenroth, A. Neels, G. Laurenczy and M. Albrecht, Organometallics, 2009, 28, 5112; F. E. Hahn, A. R. Naziruddin, A. Hepp and T. Pape, Organometallics, 2010, 29, 5283.

17 Y. Xu, A. Fischer, L. Duan, L. Tong, E. Gabrielsson, B. Akermark and L. Sun, Angew. Chem. Int. Ed., 2010, 49, 8934; L. Duan, A. Fischer, Y. Xu and L. Sun, J. Am. Chem. Soc., 2009, 131, 10397 (c) X. Sala, I. Romero, M. Rodriguez, L. Escriche and A. Llobet, Angew. Chem., Int. Ed., 2009, 48, 2842. 
for Table of Contents entry only

Tunable single-site ruthenium catalysts for efficient water oxidation

Lucile Bernet, ${ }^{a}$ Ralte Lalrempuia, ${ }^{a}$ Wadih Ghattas, ${ }^{a}$ Helge MuellerBunz, ${ }^{a}$ Laura Vigara, ${ }^{b}$ Antoni Llobet ${ }^{*}{ }^{b}$ and Martin Albrecht $*^{a}$

Ruthenium complexes comprising a broadly tunable triazolylidene ligand are efficient and robust water oxidation catalysts, producing $\mathrm{O}_{2}$ exclusively and essentially no $\mathrm{CO}_{2}$.

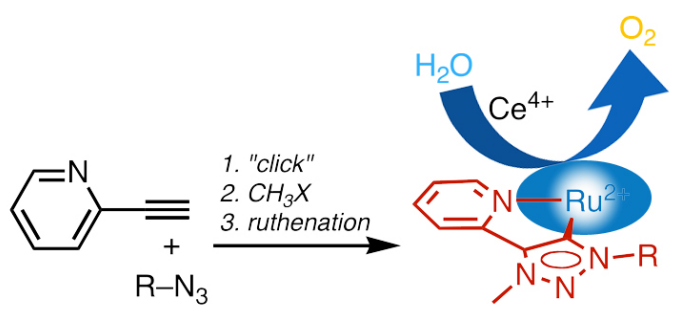


